\title{
A Virtual Tour to the Inscriptions of the UNESCO World Heritage Site St. Michael in Hildesheim
}

\author{
Anna Neovesky \\ Academy of Sciences and Literature | Mainz \\ Geschwister-Scholl-Str. 2, 55131 Mainz, Germany \\ Anna.Neovesky@adwmainz.de
}

\author{
Julius Peinelt \\ Mr. Fridge Software \\ Kottbusser Damm 8, 10967 Berlin, Germany \\ Julius@mr-fridge.de
}

\begin{abstract}
Museums, places of interest and cultural heritage sites can be often visited on the Internet. Panoramic images and virtual tours allow to access distant sites from home. But can this popular and touristic way of presentation also be used to present scientific information to a broad public? This question arose at the Academy of Sciences and Literature | Mainz regarding its project "Deutsche Inschriften Online" (German Inscriptions Online). The research project "Die Deutschen Inschriften" collects and redacts medieval and early modern inscriptions in Europe, in the areas that are today the Federal German Republic, the Republic of Austria and South Tyrol. The results are published in currently over $\mathbf{8 0}$ volumes, $\mathbf{3 3}$ of these are also accessible online. To bring the scientific edition of the inscriptions in its spatial context and make the scientific content easily accessible to the general public, a virtual tour was designed and implemented for the UNESCO World Heritage Site St. Michael in Hildesheim. The scientific approach was to make inscriptions as an important aspect of historic evidence understandable for the broad public. The thematic focus lies on the dominant figure of the early history of the church, Bishop Bernward of Hildesheim. In the tour, the user can navigate through the church. Interactive elements indicate the possibility to transfer to different viewpoints or to show information about specific points of interest - most of them inscriptions, but also information on other relevant (art-) historic artefacts. On click a pop-up opens, containing general information on the inscriptions, the full transcription and the translation of the inscription. Furthermore, images of the inscription as well as sketches and old photographs are provided. References to the critical editions of the inscriptions in "Deutsche Inschriften Online" provide an easy access to the full scientific information. An encapsulated generic software package of the tour will be released in June 2015. The software allows its users to build virtual tours for other buildings and sites without any knowledge of programming.
\end{abstract}

Virtual cultural heritage. Panoramic tour. Visualisation. Generic software. Epigraphy.

\section{INTRODUCTION}

Museums, places of interest and cultural heritage sites can be often also visited on the Internet. Panoramic images and virtual tours give access to monuments, architectural complexes, churches or further buildings and allow the user to access distant sites from home. hese virtual or panoramic tours are a visualisation of the presented site. Unlike 3D reconstructions, they usually do not include geographic data.

In general, those virtual tours offer the visual experience of the building or site. Some of those tours also provide basic textual information on the interior and the objects within the tour (e.g. see the virtual tours through the Speyer cathedral, or Buckingham Palace). But can this popular and touristic way of presentation also be used to present scientific information to a broad public?

This question arose at the Digital Academy (digitale-akademie.de), the technical department of the Academy of Sciences and Literature | Mainz and the research project "Die Deutschen Inschriften" - The German Inscriptions. The project "Die Deutschen Inschriften" was established in 1934 as an interacademic venture of epigraphical publication. It collects and redacts the medieval and early modern inscriptions in Europe in the areas that are today the Federal German Republic, the Republic of Austria and South Tyrol. The results are published in currently 81 volumes, each of them focusing on a specific geographical location (Kloos 1959).

An increasing amount of the volumes also is accessible online on the platform "Deutsche 
Inschriften Online" (inschriften.net). This project was initialised and implemented by the Academies of Sciences in Mainz and the Göttingen with the objejctive to digitise the scientific volumes of the "Deutsche Inschriften" and to make them available online. The website also features an elaborated search interface with the access to all currently available online volumes - at the moment 30 volumes with over 11,000 objects.

News and article series concerning specific epigraphical topics complete the range and give non-experts access to the subject (Schrade 2010).

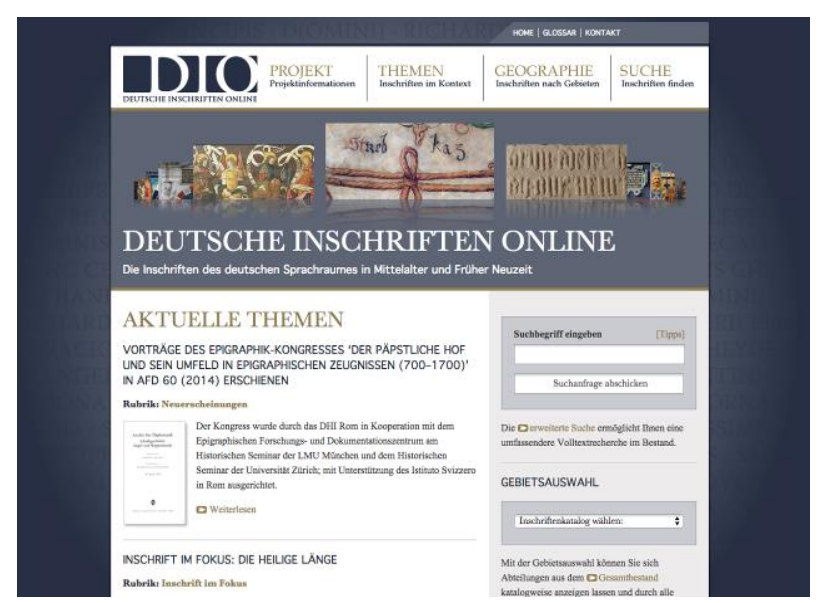

Figure 1: The epigraphical platform inschriften.net

The project presented here is the result of a cooperation between Digital Academy and the Hessian department of the project "Die Deutschen Inschriften". The goal was to create a low threshold access to the full scientific information of the inscriptions for the broad public by using the visual possibilities of a virtual tour.

The reference object is St. Michael's Church in Hildesheim. The Church is, together with St. Mary's Cathedral in Hildesheim, a UNESCO World Heritage site. This is due to their significance as being representative examples of Ottonian romanesque architecture and of Ottonian pictorial arts (UNESCO 2008).

The object was selected not only because of the church's significance, but also because of the availability of the material. Panoramic images of the church were disposable and the scientific exploitation of the inscriptions was already distributed.

In 2010, on behalf of the Academy of Sciences Göttingen, the University of Applied Sciences Mainz 3D-scanned the church's interior using terrestrial laser scanning and captured panoramic images on over 30 locations in the church interior and the crypt (Kern et al. 2011a, Kern et al. 2011b). The images and 3D data were initially made for another research purpose, but the panoramic images were also kindly provided for this virtual tour.

The scientific volumes covering Hildesheim have already been published within the series "Die Deutschen Inschriften". In 2003, the volume covering the city of Hildesheim was published and in 2008 the volume to the inscriptions of the Hildesheim district followed (Wulf 2003).

\section{A VIRTUAL TOUR THROUGH ST. MICHAEL'S CHURCH}

\subsection{Scientific conception}

The dominating figure in the early medieval history of St. Michael's is its founder Bishop Bernward of Hildesheim. Bernward, born 960 in a Saxon noble family, entered the service of the imperial court in the year 977. Later, he became the tutor of the Holy Roman Emperor Otto III. He was consecrated as Bishop of Hildesheim in 993.

Bishop Bernward was instrumental in the construction of the early Romanesque Church of St. Michael. He consecrated the yet unfinished church in 1022. The construction work was completed after Bernward's death. He is buried in the church's western crypt (Wulf 2003 \& 2008).

The key objection of the virtual tour is to impart Bernward's connection and the early history of the church (Kruse 2012). Also, it aims to illustrate the importance of inscriptions as a source of biographical evidence.

The information to the epigraphical and pictorial agenda is divided into two tours, each of them concentrating on an aspect of his involvement:

- "The church of the bishop" concentrates on Bernwards work as Bishop of Hildesheim and founder of St. Michael's: founding of the monastery, cornerstone ceremony, consecration of the church, burial and burial site.

- "The church of the saint" concentrates on Bernwards persistence beyond his death: his canonisation in the 12th century and the following destruction of church and pictorial agenda in his memory.

Comprehensive overviews about the architecture and historical events grant the viewers additional basic information. Further tours to other elements and periods in the church's history are planned, e.g. about its bi-denominational period since the 16 th century. 
The conception of thematic tours prevents the user from "getting lost" in the environment and losing the context of the visualisation and the content being transported there.
The viewer should be guided trough the tour to receive information in a sorted order. In the context of historical information this is usually chronological (Gutiérrez et. al. 2008, Rizvic 2014, Tan \& Rahman 2009).

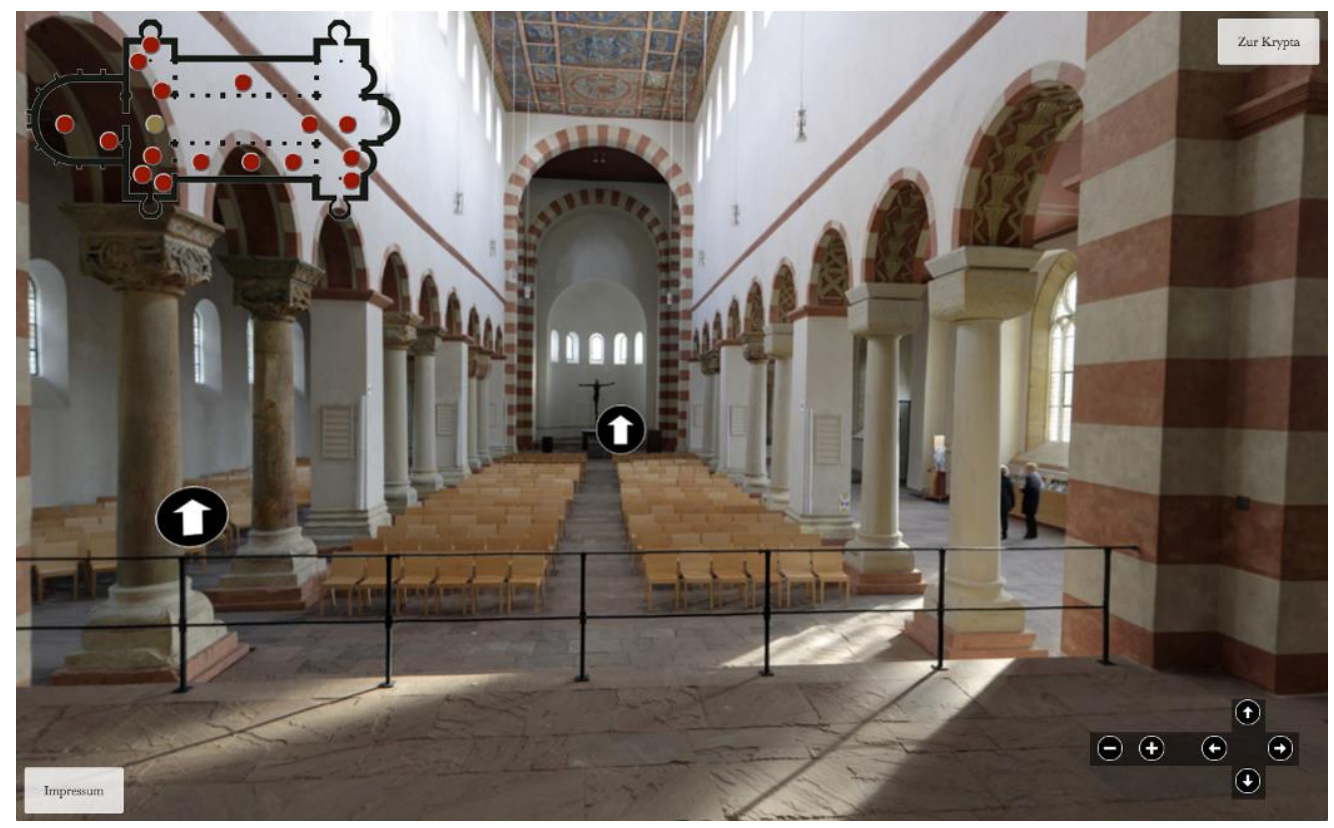

Figure 2: Virtual tour through St. Michael's Church in Hildesheim: view from the western choir through the main nave

\subsection{The virtual tour}

In the virtual tour, the user can navigate through the church via mouse, keyboard or the on-screen navigation. It is possible to zoom in for a better view on details. A map gives an overview of the current and further existing viewpoints. Clicking on a map spot will lead to that viewpoint.

Further interactive elements within the panoramic tour indicate the possibility to transfer to different viewpoints or to receive information about specific points of interest. These are mainly inscriptions, but also other selected objects such as the ceiling fresco or decorative interior. Also, some information points provide basic information about history and architecture of St. Michael's.

When clicking one of the information points, a popup will open. This pop-up contains textual and audio information to the object as well as an image.

References linked to the critical editions of the inscriptions in "Deutsche Inschriften Online" provide an easy access to the full scientific information.

The tour can be viewed on desktop computers as well as on tablets and mobile devices. This allows the user to utilise the virtual tour also as a (audio) guide on-site.

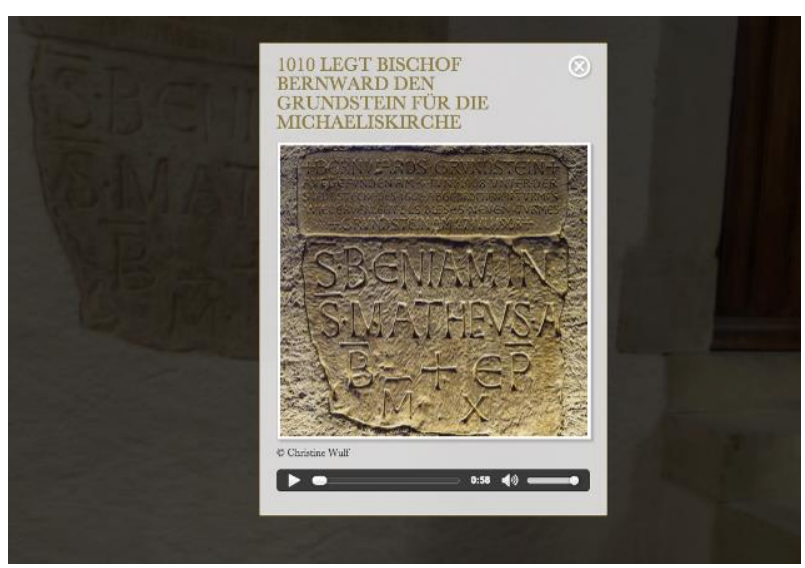

Figure3: Opened pop-up window

\subsection{Technical approach}

A first proof-of-concept was released in 2012 at the Digital Academy, when the virtual tour to the inscription of church and monastery St. Stephan in Mainz was presented (st-stephan-virtuell.de, Kern \& Neovesky 2014).

At that time, Adobe Flash in combination with the 3D-engine Away3D was chosen as the underlying technology. User analysis was carried out on the inschriften.net website to identify the users hardware and browser. They showed that, due to 
the older Browser versions used, no other technology - such as HTML5 and WebGL - would be supported (Neovesky 2012).

The project "St. Stephan virtuell" was also a technical proof of concept regarding the format for the communication between the application and the content and its generic integration.

All images, preferences and content are stored in a JSON file (json.org). JSON is a format for data structuring, usually used for the communication between a server and a web application. Data objects are specified as key-value pairs (ECMA 2013). For example, the name of an image is the key and the value would be the link to its source (the path to the document, e.g. a URL).

One great advantage of JSON is that it is humanreadable and no further knowledge of a programming language is needed to edit it. The application loads all files and settings from the JSON file.

This taxonomy was also used for another research project at the Academy of Sciences in Mainz and the University of Applied Sciences Mainz: "Inscriptions in their Spatial Context". The research project develops research methods and software tools for Spatial Humanities research on the 3Dgeometry of environments like building interiors. Geometric data, drawn from geometric scannings, are semantically enriched and connected to scientific textual and visual data (Unold \& Lange 2014) .

These preliminary work was used for the virtual tour in Hildesheim. Some concepts were further developed and state of the art technology was used to allow browser and device independence. The main goal in the development process was not only to create a virtual tour through St. Michael's in Hildesheim, but to create a generic tool that would enable to create virtual tours for other objects as well.

However, the panoramic tour is not a method of reconstruction, but of visualisation. No geographic data lies behind the images and a free walk-around out of the existing viewpoints is not possible.

The virtual tour through Hildesheim is implemented as a generic JavaScript application using HTML5, WebGL and the Three.js framework.

Three.js is a JavaScript 3D graphics library. It allows the creation and animation of 3D graphics that can be displayed on a web browser (Sukin 2013). No plugins or add-ons for the browser are necessary since Three.js uses WebGL, a JavaScript API for rendering 3D computer graphics by using the HTML5 canvas element and utilising the graphical processing unit of the computer.

For display, the virtual tour requires a Web browser with WebGL support. All modern browsers support WebGL (caniuse.com).

The used technologies suggest to load needed resources dynamically instead of preloading all of them before the virtual tour can be used. This prevents long loading times at the beginning and enables the creator of a tour to customise the needed data volumes for different requirements without the need to redeploy a whole application but by changing single parts.

Various programming and mark-up languages have been used for the software, all of them are open standards: JavaScript for application logic, HTML5 for the markup of the items to be displayed (general container, pop-up window and other text) and CSS for the styling of these elements. As mentioned above, the JSON format was used for data transmission.

\section{A GENERIC SOFTWARE FOR VIRTUAL TOURS}

In June 2015 the generic software will be released,. It enables others to build their own virtual tours. The software will be distributed in two different ways: as an extension within the Content Management System TYPO3 and as a standalone package.

The software is licensed with the GNU General Public License, a free software license. This allows the user not only to use the software, but also to share and modify it (Free Software Foundation 2007).

The TYPO3 extension can be deployed on all websites realised with the TYPO3 content management system (TYPO3 CMS). It provides the full source code and a graphical user interface. The extension virtual_tour can be obtained at the TYPO3 extension repository and supports the TYPO3 version 6.0 or higher.

The extension provides a graphical user interface. The user can configure the extension and embed pictures, maps as well as the information to be shown in the panoramic tour without the need to touch the code base. A manual describes the existing settings and workflows.

The JavaScript application is available on GitHub under https://github.com/digicademy/virtualTour. It can be used for online publication as well as on offline devices. It is possible to launch and 
configure the tour offline, as a local server is also provided in the package. Possible application areas are for example exhibitions or presentations.

Even though this package does not contain a graphical user interface, a documentation and a clear structure make the system usable for nonprogrammers. Of course, users with coding skills or a understanding of HTML and CSS will be capable to make more individual tours.

From the start, the package offers a simple tour containing some exemplary content and schemas to all necessary configuration files and formats, such as the JSON file, the positioning of map and navigation.

The content (panoramic images, text, audio, links) can be added to the particular folder. Also, it is possible to extend the type of information provided - for example with videos - as well as the functionality and design of the tour.

By using the JSON file for configuration and data exchange, it is possible to create custom virtual tours by just adding own images, positions and text.

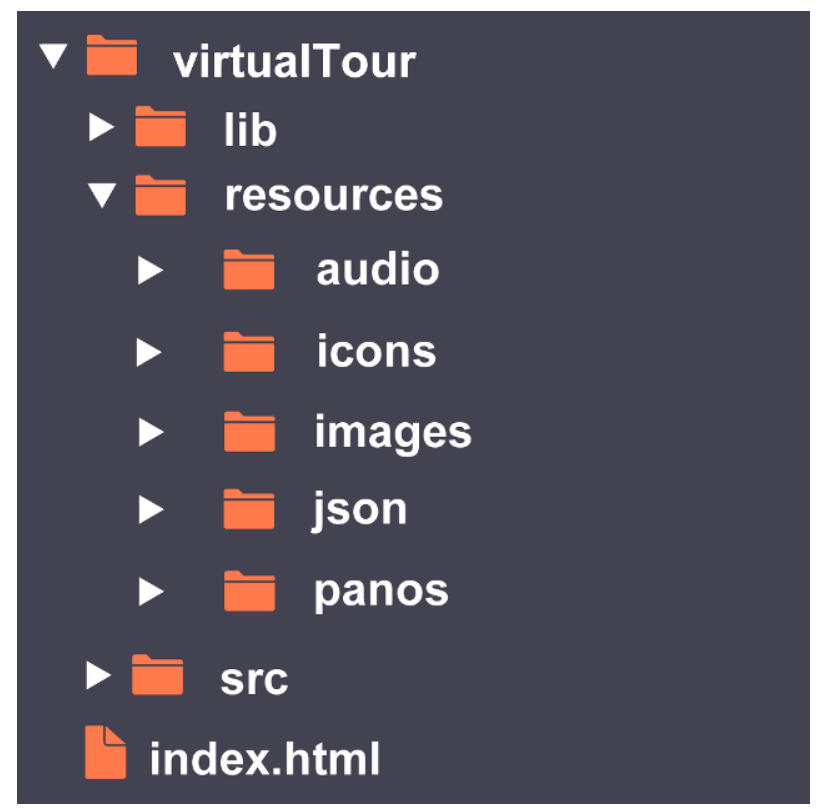

Figure 4: The directory structure of the software

\section{CONCLUSION}

The virtual tour to the inscriptions of St. Michael's Church in Hildesheim was born from the idea of combining a popular visual representation with the unrestricted access to scientific research results and publications.
The created software is not limit to the use at this specific object. As it is generic, it can be adapted in other (research) projects.

Even though the focus of the application is on the broad public, the visualisation can be also interesting for researchers from diverse disciplines to get a spatial impression from distant sites. The high-resolution panoramic images enable the viewers to zoom in on details.

The software is released Open Source, which makes it widely applicable. Also research projects with a smaller financial leeway can include a visualisation in their presentation and online publication. Also, it can be used as a proof of concept for further development in the area of virtual heritage in more extended technologies, such as 3D-reconstruction or Augmented Reality.

The distribution under a free license enables users to extend the code and adjust it to their projects needs.

\section{REFERENCES}

ECMA (2013) The JSON Data Interchange Format. In ECMA International (ed.), Standard ECMA-404, Geneva.

Kern, F., Bruhn, K.-Ch., Mehlig, S., \& Siegrist, B. (2011a) Messtechnik und Inschriftenforschung: Anwendungsbezogene Arbeiten in St. Michaelis zu Hildesheim. Allgemeine Vermessungs-Nachrichten, 118(11/12), pp. 381-390.

Kern, F., Mehlig, S., \& Siegrist, B. (2011b) Geometrische Qualität von aus Einzelphotos zusammengesetzten Panoramen. In Seyfert, E. (ed.) Publikationen der Deutschen Gesellschaft für Photogrammetrie, Fernerkundung und Geoinformation e.V., 20, pp. 129-136.

Kern, S., \& Neovesky, A. (2014) St. Stephan virtuell - Inschriften als Zeugnisse der 1000-jährigen Stiftsgeschichte von St. Stephan im Mainz im Web. In Flothmann, H. (ed.) Jour fixe Büchlein Kulturtreff der Freunde Gutenbergs, Internationale Gutenberg-Gesellschaft in Mainz e.V., Mainz.

Kloos, R. M. (1959) Die deutschen Inschriften (=The German inscriptions). Deutsches Archiv für Erforschung des Mittelalters, 15, pp. 177-181.

Kruse, K.-B. (2012) Zur Bautätigkeit Bischof Bernhards in Hildesheim. In Lutz, G. (ed.) 1000 Jahre St. Michael in Hildesheim. Imhof, Petersberg, pp. 41-65. 
Gutiérrez, M., Vexo, F., \& Thalmann, D. (2008) Stepping into Virtual Reality, Springer,

Neovesky, A. (2012) St. Stephan virtuell - ein internetgestützter Panoramarundgang durch die Mainzer Stephanskirche - Entwicklung und Umsetzung eines Projektes im Bereich der digitalen Geisteswissenschaften. Skriptum, 2(2), URN: urn:nbn:de:0289-2012110220 (retrieved 15 March 2015).

Rizvic, S. (2014) Story Guided Virtual Cultural Heritage Applications. Journal of Interactive Humanities, 2(1), Article 2. DOI: 10.14448/jih.02.0002.

Schrade. T. (2012) Vom Inschriftenband zum Datenobjekt. Die Entwicklung des epigraphischen Fachportals „Deutsche Inschriften Online." (=From scholarly edition to data object. The evolution of the scholarly web portal "German Inscriptions Online"). In N. Henkel (ed.), Inschriften als Zeugnisse kulturellen Gedächtnisses - 40 Jahre Deutsche Inschriften in Göttingen. Beiträge zum Jubiläumskolloquium vom 22. Oktober 2010 in Göttingen, Reichert Verlag, Wiesbaden, pp. 59-72.

Sukin, I. (2013) Game Development with Three.js, Packt Publishing, Birmingham.

Tan, B. K., \& Rahaman, H. (2009) Virtual heritage: reality and criticism. In T. Tidai and T. Dorta (eds.), Joining Languages, Cultures and Visions: CAADFutures 2009, PUM, 2009, pp. 143-156.

UNESCO (2008) St Mary's Cathedral and St Michael's Church at Hildesheim, URL: http://whc.unesco.org/en/list/187 (retrieved 15 March 2015)

Unold, M., \& Lange, F. (2014) Relating texts to 3Dinformation: A generic software environment for Spatial Humanities. Digital Humanities '14 (DH 2014), Lausanne, CH, 7-12 July 2015, URL: http://dharchive.org/paper/DH2014/Paper-680.xml (retrieved 15 March 2015).

Wulf C. (2003) Die Inschriften der Stadt Hildesheim, gesammelt und bearbeitet von Christine Wulf. Die Deutschen Inschriften 58,
Wiesbaden. urn:nbn:de:0238-di058g010e006 (retrieved 15 March 2015).

Wulf, C. (2008) Bernward von Hildesheim, ein Bischof auf dem Weg zur Heiligkeit. Concilium Medii Aevi Bd, 11, pp. 1-19.

\section{Internet sources:}

caniuse.com, http://caniuse.com/\#feat=webgl (retrieved 15 March 2015)

digitale-akademie.de, http://www.digitaleakademie.de (retrieved 15 March 2015).

Free Software Foundation (2007) GNU General Public License https://gnu.org/licenses/gpl.html (retrieved 15 March 2015).

inschriften.net, http://www.inschriften.net (retrieved 15 March 2015).

JSON, http://www.json.org (retrieved 15 March 2015).

st-stephan-virtuell.de, http://st-stephan-virtuell.de (retrieved 15 March 2015).

Three.js, http://threejs.org (retrieved 15 March 2015).

TYPO3 CMS, http://typo3.org (retrieved 15 March 2015).

TYPO3 Extension Repository, http://typo3.org/extensions/repository (retrieved 15 March 2015).

Virtual tour through the Buckingham Palace, http://www.royal.gov.uk/virtualtours/BuckinghamPal aceVirtualTour/throne room.html (retrieved 15 March 2015).

Virtual tour through the Speyer cathedral, http://kaiserdom-virtuell.de (retrieved 15 March 2015).

virtualTour, https://github.com/digicademy/virtualTour (retrieved 15 March 2015). 